\title{
Long Term Compression Strength of Mortars Produced Using Coarse Steel Slag as Aggregate
}

\author{
Erika Furlani and Stefano Maschio \\ Dipartimento Politecnico di Ingegneria e Architettura, Università di Udine, Via delle Scienze 206, 33100 Udine, Italy \\ Correspondence should be addressed to Erika Furlani; erika.furlani@uniud.it
}

Received 20 July 2016; Revised 12 September 2016; Accepted 20 October 2016

Academic Editor: Gianmarco de Felice

Copyright ( 2016 E. Furlani and S. Maschio. This is an open access article distributed under the Creative Commons Attribution License, which permits unrestricted use, distribution, and reproduction in any medium, provided the original work is properly cited.

\begin{abstract}
The paper reports on some experimental results obtained from the production of mortars prepared using a commercial cement, coarse steelmaking slag, superplasticizer, and water. The behaviour of this reference composition was compared to that of some others containing further additives in order to investigate materials compressive strength after long time ageing. It has been demonstrated that an optimized water/cement ratio coupled with slag particles of size lower than $2.5 \mathrm{~mm}$ and proper protocol of preparation leads to the production of materials with good mechanical properties after 28,90 , and 180 days of ageing. The resulting materials therefore appeared as good candidates for civil engineering applications. However, the present research also demonstrates that the mortar samples of all of the compositions prepared suffer from decay and compressive strength decrease after long time ageing in water. In the present paper the results are explained taking account of materials residual porosity and alkali silica reaction which occurs in the samples.
\end{abstract}

\section{Introduction}

Steelmaking slag (SS) is obtained in large quantities from steel production. It is known that the production of one ton of steel implies the production of $130-200 \mathrm{~kg}$ of slag, depending on the composition of the steel and on the steel production process. The great amount of SS produced all over the world implies that their recycling is presently necessary not only due to the rising cost of their possible landfill disposal which is reflected on the cost of the steel produced, but also as a consequence of the "zero-waste" objective which must be the final goal of all future human activities. In fact, it is generally accepted that a possible way for SS recycling is the preparation of roadways embankment which however could have effects on environment due to their natural elution.

SS derives from a high temperature process and, as a consequence of its large lime content, is made unstable by two phenomena: the first is due to the presence of $2 \mathrm{CaO} \mathrm{SiO}_{2}$, which can transform, on cooling or later, into a phase with a larger specific volume [1] crumbling the slag which results in a mixture of submicronic-micronic-granulated particles; the second phenomenon is due to the presence of free lime which causes grains swelling for hydration in atmospheric environment after cooling. Such volumetric instabilities are a great disadvantage when slag is used as a raw material for recycling. When the slag also contains free $\mathrm{MgO}$ or $\mathrm{MgO}$ based compounds, the above phenomena are coupled with a retarded hydration which, in general, occurs when these products are present in mortars or concrete $[2,3]$. In order to obtain sufficient stability, various methods have been proposed like long time weathering of the granulated slag outside the slag pits, treatment of the liquid slag by injecting oxygen and silica, autoclaving of the slag in slag baskets $[4,5]$, and others [6-8].

It is generally accepted that steelmaking slag recycling is convenient provided that the resulting materials have good durability and maintain properties at least equal to the limits established by the official standards for production after long time ageing.

Several authors proposed the use of cement blended with SS for concrete manufacturing [9-11]; for such application, SS needs to be converted, by milling, into a powdered product.

Other authors have found that good properties could be obtained if SS are used for a partial replacement of sand fines with optimized replacement ratios [2, 3, 12-15]. 
TABLE 1: Mortars mix proportions and samples symbolic names.

\begin{tabular}{lcccc}
\hline & Reference & Chromium oxide & Ultramarine & Aluminium silicate (Na) \\
\hline Cement $(\mathrm{g})$ & 550 & 550 & 550 & 550 \\
Slag $(\mathrm{g})$ & 1650 & 1650 & 1650 & 1650 \\
s/c & 0.015 & 0.015 & 0.015 & 0.015 \\
w/c & 0.36 & 0.36 & 0.36 & 0.36 \\
Chromium oxide $(\mathrm{g})$ & - & - & 66 & - \\
Ultramarine (g) & - & - & - & 66 \\
Aluminium silicate $(\mathrm{Na})(\mathrm{g})$ & - & - & 6 \\
\hline
\end{tabular}

Independently on their chemical composition, SS normally displays a wide particle size distribution which also depends on the slag origin, the steel production process, and the time elapsed from slag generation. SS morphologic characteristics are an additional parameter that must be taken under consideration during mortars or concrete preparation.

Nowadays, the use of SS containing small as well as coarse particles, for mortars or concrete production, is still matter of discussion [16].

The aim of the present paper is to report and discuss compressive strength data obtained from mortars containing cement, coarse steel slag, superplasticizer, and water. Mortars were produced using a fixed slag/cement ratio (1/3), as it has been often proposed in literature [13, 17-19]: a fixed superplasticizer/cement ratio (s/c) and a fixed water/cement ratio (w/c). Materials were aged in water for different times up to the limit of 1100 days (d). The reference composition was then modified by the addition of $3 \mathrm{wt} \%$ of the total solid material content by several compounds, namely, ultramarine, aluminium silicate $(\mathrm{Na})$, and the green colour (chromium oxide). Hydrated products were characterized by compressive strength and water absorption tests after 28, 90, 360, 720, and $1100 \mathrm{~d}$.

\section{Experimentals}

2.1. Materials. Starting materials for mortars preparation were a commercial CEMIIB-LL $32.5 \mathrm{~N}$ cement; the superplasticizer Glenium 51 (BASF); a steel slag, obtained from the production of a chromium-manganese austenitic steel by a rotary kiln, as aggregate; and water. This reference composition, hereafter called $\mathrm{R}$, was then modified by the addition of $3 \%$ of the total starting solid mass with one of the following powders: 817B-ultramarine colour (SIOF spa: Società Italiana Ossidi Ferro, Pozzolo Formigaro-Vr, Italy), Na-aluminium silicate $\left(82 \% \mathrm{SiO}_{2}, 9.5 \% \mathrm{Al}_{2} \mathrm{O}_{3}, 8 \% \mathrm{Na}_{2} \mathrm{O}\right.$; Fluka Analytical), and 812B-green chromium oxide (SIOF spa: Società Italiana Ossidi Ferro, Pozzolo Formigaro-Vr, Italy). Mortars mix proportions and samples symbolic names are reported in Table 1.

2.2. Characterization of the Starting Materials. The slag was previously naturally weathered for one month outside the production plant; after that it was thoroughly wet and then milled by a hammer mill in order to reduce the maximum particle dimension below the size of $2.5 \mathrm{~mm}$. SS contains $2 / 3$ of fines and $1 / 3$ of coarse particles. In the present research,
TABle 2: Composition, LOI, and density of CEII/B-LL and SS. "Others" indicates the cumulative quantity of all oxides determined in quantity lower than $0.1 \mathrm{wt} \%$.

\begin{tabular}{lcc}
\hline Component & CEMIIB-LL $(w t \%)$ & SS $(w t \%)$ \\
\hline $\mathrm{CaO}$ & 62.3 & 38.2 \\
$\mathrm{SiO}_{2}$ & 19.8 & 14.8 \\
$\mathrm{Al}_{2} \mathrm{O}_{3}$ & 4.2 & 7.4 \\
$\mathrm{MgO}$ & 2.5 & 11.7 \\
$\mathrm{Na}{ }_{2} \mathrm{O}$ & 0.6 & - \\
$\mathrm{K}_{2} \mathrm{O}$ & 1.1 & - \\
$\mathrm{Fe}_{2} \mathrm{O}_{3}$ & 3.2 & 9.8 \\
$\mathrm{MnO}$ & 0.6 & 10.4 \\
$\mathrm{Cr}_{2} \mathrm{O}_{3}$ & - & 2.0 \\
$\mathrm{~V}_{2} \mathrm{O}_{5}$ & - & 0.8 \\
$\mathrm{P}_{2} \mathrm{O}_{5}$ & - & 1.2 \\
$\mathrm{SO}_{4}{ }^{2-}$ & 2.9 & - \\
Others & 2.8 & 3.7 \\
Free lime & - & 1.9 \\
LOI $(\%)$ & 4.25 & - \\
Density $\left(\mathrm{g} / \mathrm{cm}^{3}\right)$ & 2.46 & 3.29 \\
\hline
\end{tabular}

${ }^{*}$ The amount of free $\mathrm{CaO}$ was previously measured following the ethylene glycol method.

fines are considered the slag fraction containing particles with size $<1000 \mu \mathrm{m}$.

The chemical analysis of the slag and that of the cement, determined by a SpectroMass 2000 induced coupled plasma (ICP) mass spectrometer, is reported, in terms of oxides, in Table 2. The amount of free lime in the slag was also determined following the ethylene glycol method. The density was determined following the ASTM C127 and C128 norms; results are averaged over the fine and coarse slag fractions.

Crystalline phases of slag and cement were investigated by X-ray diffraction (XRD). XRD patterns were recorded on a Philips X'Pert diffractometer operating at $40 \mathrm{kV}$ and $40 \mathrm{~mA}$ using $\mathrm{Ni}$-filtered $\mathrm{Cu}-\mathrm{K} \alpha$ radiation. Spectra were collected using a step size of $0.02^{\circ}$ and a counting time of $40 \mathrm{~s}$ per angular abscissa in the range of $20-80^{\circ}$. Philips X'Pert High Score software was used for phase identification.

An Horiba LA950 laser scattering instrument was used to investigate the particles size distribution (PSD) of slag fines and cement: analyses were made in water after $3 \mathrm{~min}$ sonication. For clarity of comprehension all PSD curves are represented with logarithmic abscissa and reported in Figure 1. 


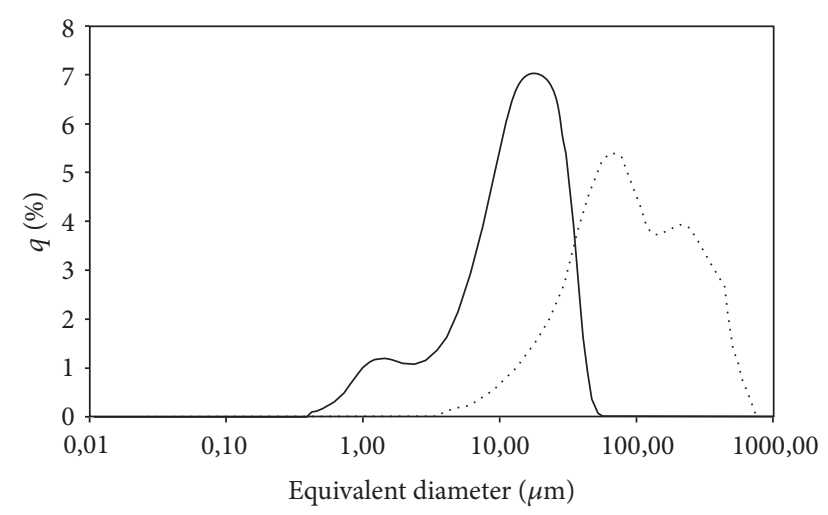

Figure 1: Particle size distribution of the fine fraction of slag (interrupted line) and CEMIIB-LL (plain line).

2.3. Mortars Preparation. For the mixture preparation and w/c optimization a $5 \mathrm{~L}$ Hobart planetary conforming to ASTM C305 standards was used. The optimized amount of water was determined by the ASTM C1437 slump test performed on the reference blend $\mathrm{R}$. The paste is said to have the right workability if the cake width is $180( \pm 20) \mathrm{mm}$, according to UNI 7044:1972 and ASTM C230 norms. The identified optimal w/c ratio of the reference blend $(\mathrm{R})$ was 0.36 ; this same ratio was applied to all the compositions.

All mortar pastes were prepared by the following protocol: the full amount of slag was put into the mixer together with the total amount of water and superplasticizer and mixed for two minutes; after this previous homogenization, also the additive was introduced into the mixer and the paste was stirred for $15 \mathrm{~min}$. This time elapsed, cement was added, and the product was worked on for $5 \mathrm{~min}$.

Pastes were then poured under vibration into the moulds with dimensions of $100 \times 100 \times 100 \mathrm{~mm}$ (for compression tests) or $40 \times 40 \times 40 \mathrm{~mm}$ (for water absorption tests), sealed with a plastic film to ensure mass curing, and aged $24 \mathrm{~h}$ for a first hydration. Samples were then demoulded and cured in air for $24 \mathrm{~h}$ and then in water at room temperature for $28,90,180,360,720$, and $1100 \mathrm{~d}$. After production, materials ageing was performed separately to avoid contamination between the different compositions. The ageing water was maintained at the constant temperature of $25^{\circ} \mathrm{C}\left( \pm 3^{\circ} \mathrm{C}\right)$ and replaced with fresh water every $7 \mathrm{~d}$. After curing, before their characterization, samples were dried with a cloth and aged in the atmosphere for $24 \mathrm{~h}$.

Materials ageing by submersion in water was set up in order to study their behaviour under severe conditions and consequently to test their behaviour in an eventual use under moist environment. In absence of an autoclave treatment such ageing was considered suitable for products where the retarded hydration could have negative impact on their durability.

2.4. Characterization of Hydrated Materials. A modified ASTM C 642 norm was used to test water absorption of the hydrated samples. After curing, samples were put in an oven at $80 \pm 5^{\circ} \mathrm{C}$ for $24 \mathrm{~h}$ and weighed $\left(W_{1}\right)$; they were then aged in an autoclave, at $120^{\circ} \mathrm{C}$ and $2 \mathrm{kPa}$ for $2 \mathrm{~h}$ using $2 \mathrm{~L}$ of water.
After boiling, they were cooled down to room temperature (in water), dried with a cloth, and weighed again $\left(W_{2}\right)$. Water absorption was evaluated using the following equation:

$$
W(\%)=\frac{100\left(W_{2}-W_{1}\right)}{W_{1}} .
$$

Compression tests were performed, in accordance with the ASTM C39 norm, using Test Mark CM8000 apparatus; data were averaged over 3 measurements.

Expansion was measured by a caliper, before the compression tests after $360 \mathrm{~d}$ of curing, on $100 \times 100 \times 100 \mathrm{~mm}$ cubic samples.

\section{Results and Discussion}

During weathering, the slag was often turned over in order to favour any possible natural hydration of the unstable components. Such compounds, if present in the fine fraction of the slag, simply contribute to materials' expansion during the first hydration step when materials are not yet hardened $[2,3]$. However, if they present as clusters of particles, more or less stuck together, they suffer from uncontrollable hydration which could occur after mortars hydration when materials are brittle. The reduction of the maximum particles dimension below the size of $2.5 \mathrm{~mm}$ permits to optimize the contact with water during weathering, during hammer milling, and then, after that, during the stirring steps of mortars preparation.

Table 2 shows that the slag contains large amounts of $\mathrm{CaO}$, $\mathrm{SiO}_{2}, \mathrm{Fe}_{2} \mathrm{O}_{3}, \mathrm{MgO}, \mathrm{MnO}$, and $\mathrm{Al}_{2} \mathrm{O}_{3}$. All the other oxides have been detected in lower quantities even if the amount of $\mathrm{Cr}_{2} \mathrm{O}_{3}$ cannot be considered negligible. The absence of relevant amounts of toxic elements can also be remarked. Table 2 also shows that free lime is $1.9 \%$ and the ratio $(\mathrm{CaO}+\mathrm{MgO}) /$ $\mathrm{SiO}_{2}$ is superior to 1.4 which would lead to expectation of hydraulic activity [20-23]. It can also be observed that density is $3.29 \mathrm{~g} / \mathrm{cm}^{3}$, in line with those reported by other researchers $[10,13,24]$. CEM II/B-LL conforms to European Standards EN-197/1.

Figure 1 shows the PSD curves of the fine fraction of slag and cement. It can be observed that cement displays a maximum concentration of particles at around $20 \mu \mathrm{m}$ but contains also a little fraction of smaller particles highlighted by a small peak at around $1.5 \mu \mathrm{m}$; the milled and sieved $(1000 \mu \mathrm{m})$ SS has a PSD with a very large particle size distribution highlighted by a double peak with maximum at around 80 and $350 \mu \mathrm{m}$, respectively.

The XRD analysis demonstrates that the slag contains several phases, some of them in very small amount so that it has not been possible to doubtless recognize them; the present paper, therefore, reports only those that were identified by a minimum of four representative peaks. In detail, the presence of aluminium calcium oxide (PDF 00-006-0495 $\mathrm{Ca}_{3} \mathrm{Al}_{2} \mathrm{O}_{6}$ ), pyroxmangite (PDF 01-084-1774 $\mathrm{Mg}_{0.97} \mathrm{Mg}_{0.03} \mathrm{SiO}_{3}$ ), glaucochroite (PDF 00-014-0376 (Ca, $\mathrm{Mn})_{2} \mathrm{SiO}_{4}$ ), iron oxide (PDF 01-084-0308 $\mathrm{Fe}_{2} \mathrm{O}_{3}$ ), calcium silicate (PDF 01-076-0799 $\mathrm{Ca}_{2} \mathrm{SiO}_{4}$ ), and calcium magnesium silicate (PDF 00-013-0498 $\mathrm{Ca}_{6.1} \mathrm{Mg}_{1.1} \mathrm{Si}_{3.6} \mathrm{O}_{14.4}$ ) has been 


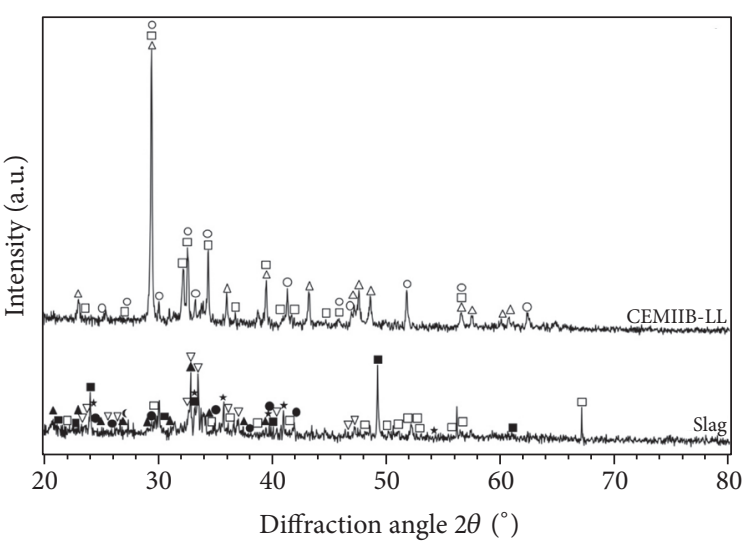

(a)

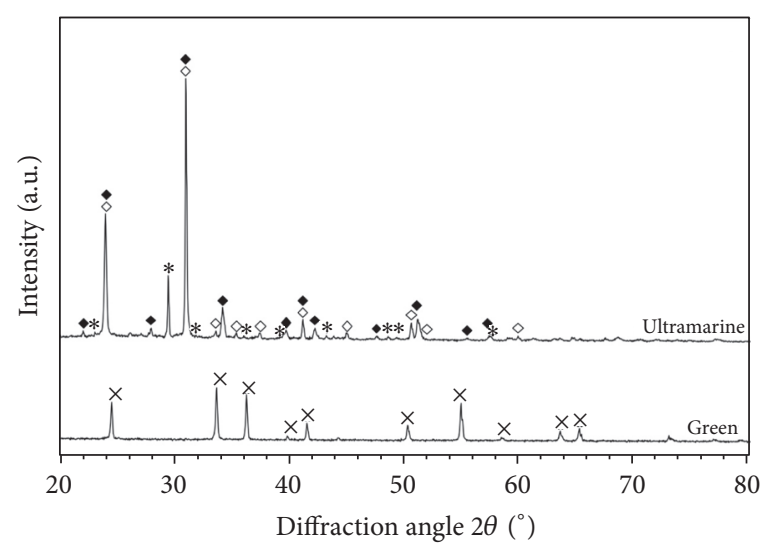

(b)

Figure 2: (a) X-ray diffraction patterns of CEMIIB-LL and slag. It is showed that cement contains calcite $(\triangle)$, C3S $(O)$, and C2S ( $\square$ ) whereas the slag contains calcium aluminium oxide $(\boldsymbol{\Delta})$, pyroxmangite $(\bullet)$, glaucochroite $(\boldsymbol{\square})$, iron oxide $(\star)$, calcium silicate $(\square)$, and calcium magnesium silicate $(\nabla)$; (b) X-ray diffraction patterns of ultramarine and green colour: ultramarine contains ankerite $(\diamond)$, sodium aluminium silicate $(\diamond)$, and magnesium calcite $(*)$; green colour is mainly chromium oxide whose peaks are identified by $(\times)$.

revealed. The presence of the above phases is documented by Figure 2(a) which also shows that CEMIIB-LL contains C3S (PDF 01-073-1929 $\mathrm{Ca}_{3} \mathrm{SiO}_{5}$ ), C2S (see above), and calcite (PDF 01-088-1807). X-ray diffraction also confirmed that green colour is mainly chromium oxide (PDF 01074-0326 $\mathrm{Cr}_{2} \mathrm{O}_{3}$ ), whereas ultramarine, which is known to be a complex sulfur-containing sodium aluminium silicate $\left(\mathrm{Na}_{8-10} \mathrm{Al}_{6} \mathrm{Si}_{6} \mathrm{O}_{24} \mathrm{~S}_{2-4}\right)$, also revealed the presence of ankerite (PDF 00-012-0088 Ca $\left(\mathrm{Mg}_{0.67} \mathrm{Fe}_{0.33}{ }^{+2}\right)\left(\mathrm{CO}_{3}\right)_{2}$ ) and a calcite modified by a small amount of $\mathrm{Mg}$ (PDF 01-089-1306 $\left.\left(\mathrm{Mg}_{0.06} \mathrm{Ca}_{0.94}\right)\left(\mathrm{CO}_{3}\right)\right)$ as it can be observed in Figure 2(b).

In the present experimental work, components homogenization, during mortars preparation, has an important but not the most important role for the production of stable materials. In the experimental section, it has been already described that slag was previously worked in order to reduce the size of coarse particles and, at the same time, to favour hydration of the major part of its hydraulic compounds. However, after milling, the slag still contains large clusters whose core could never be wet by water thus maintaining hydraulic activity even after mortar pastes production. Such hydraulic activity could then emerge when materials are in use. In fact, if their hydration occurs after demoulding on hydratedhardened materials, unwanted fractures, spalling, and/or chipping could appear. The preparation protocol followed in the present research favours an almost good hydration of the hydraulic compounds of the slag; nevertheless, after long term ageing in water, several compositions displayed the above phenomena as documented by Figures 3(a) and 3(b) which show the surface of the reference samples after 1 year of ageing in water.

It is clear that hydration is favoured by a high quantity of water coupled with a long mixing time. On the other hand, it is known that a high amount of water is in conflict with the production of materials with low open porosity and good mechanical performances. The addition of superplasticizer was therefore considered necessary for the production of fluid pastes and, after hydration, of materials with strength in line with the official norms.

In addition, it has been observed that, during mortar paste homogenization, at the early stage of mixing, the mixture containing slag, superplasticizer, water, and additive behaves like moist soil that turns into a fluid slurry after about $10 \mathrm{~min}$. This particular rheological behaviour is probably due to bleeding which is amplified by the quite high level of $\mathrm{MgO}$ which is contained in the slag $[9,18]$.

Figure 4 shows compressive strength (a) and water absorption (b) trends of samples tested after 28, 90, 180, 360, 720 , and $1100 \mathrm{~d}$; error bars are also reported.

In Figure 4(a), it is observed that the reference composition displays a strength of $35 \mathrm{MPa}$ after $28 \mathrm{~d}$ which raises to 47 after $90 \mathrm{~d}$ and remains constant up to $180 \mathrm{~d}$ but decreases for longer ageing times: samples tested after 360 and $720 \mathrm{~d}$ show a strength of 44 and $26 \mathrm{MPa}$, respectively. After such ageing time, cubic specimens self-crumbled and were not tested. In parallel, the corresponding water absorption data (Figure $4(\mathrm{~b}))$ are 6.5 after $28 \mathrm{~d}$ and 5.2 after 90 ; this value remains almost constant after 180 to $360 \mathrm{~d}$ but grows for longer ageing times reaching the value of 7.7 after $720 \mathrm{~d}$.

The behaviour of the composition containing aluminium silicate (Na) can be also observed in Figures 4(a) and 4(b). It is displayed that samples have a constant compressive strength of $55 \mathrm{MPa}$ between 28 and $180 \mathrm{~d}$ but decreases to $48 \mathrm{MPa}$ after 360. For longer times, samples self-crumble on ageing and therefore were not tested at 720 and $1100 \mathrm{~d}$; the water absorption is 4.2 after $28 \mathrm{~d}$ and remains almost constant up to $180 \mathrm{~d}$ but increases to 4.8 at $360 \mathrm{~d}$.

Materials containing ultramarine display a strength of $68 \mathrm{MPa}$ after $28 \mathrm{~d}$ which raises to 76 after 90 and 78 after 180 but decreases to 76 after $360 \mathrm{~d}, 63$ after $720 \mathrm{~d}$, and 49 after $1100 \mathrm{~d}$; the corresponding water absorption is 3.6 after $28 \mathrm{~d}, 3.2$ after $90 \mathrm{~d}$, and 2.9 after $180 \mathrm{~d}$; this value remains 


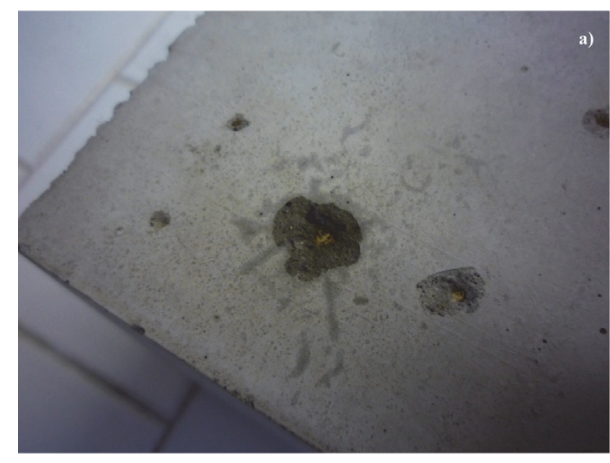

(a)

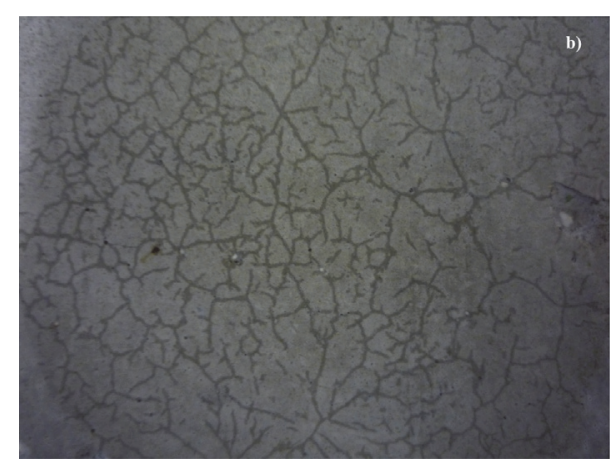

(b)

FIGURE 3: Image of the surface of the reference mortar sample after 1 year of ageing in water: (a) spalling; (b) chipping.

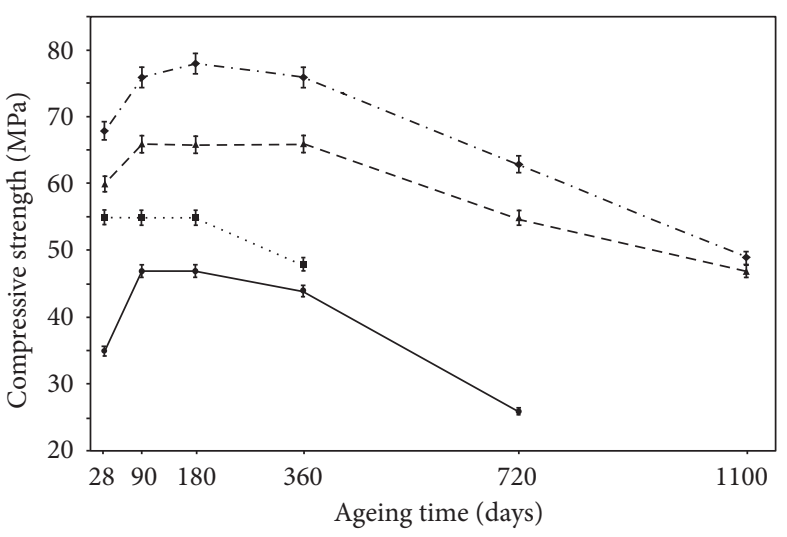

(a)

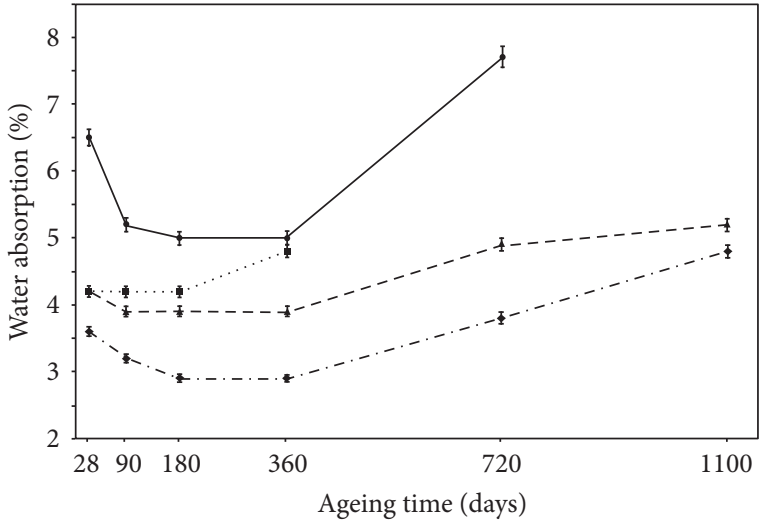

(b)

FIGURE 4: Trends of compressive strength (a) and water absorption (b) displayed as a function of curing time. Each composition refers to the following graphic: reference $=-$; chromium oxide $=---$; ultramarine $=-\cdot-\cdot-$; aluminium silicate $(\mathrm{Na})=\cdots$.

almost constant from 180 to $360 \mathrm{~d}$ but grows for longer ageing times reaching the values of 3.8 and 4.8 after 720 and $1100 \mathrm{~d}$, respectively.

Materials containing chromium oxide display a strength of $60 \mathrm{MPa}$ after $28 \mathrm{~d}$ which raises to 66 after 90; strength remains at this level after 180 and $360 \mathrm{~d}$ of ageing but slowly decreases for longer times showing $55 \mathrm{MPa}$ after 720 and 47 after $1100 \mathrm{~d}$, respectively. Water absorption is 4.2 after $28 \mathrm{~d}, 3.9$ between 90 and $360 \mathrm{~d}, 4.9$ after $720 \mathrm{~d}$, and 5.2 after $1100 \mathrm{~d}$.

Expansions of 0.044 and $0.021 \%$ were, respectively, measured on reference composition and on that containing aluminium silicate $(\mathrm{Na})$ whereas materials made with ultramarine and green colour showed 0.014 and 0.017 , respectively, with all of them being below the $0.05 \%$ limit established by the ASTM C33 official norm.

The behaviour of the reference composition is reasonably due to the synergic effect of the above described phenomena, that is, extended fracturing, chipping, and crazing, which cause catastrophic expansion in the samples during long time ageing. Data reported demonstrate that the mortars preparation protocol followed in the present research is not sufficient to favour a complete hydration of the hydraulic components contained into the coarse slag particles.
In materials containing aluminium silicate $(\mathrm{Na})$, the presence of $\mathrm{Na}$ favours the ASR which increases the initial residual porosity and, in turn, materials permeability, accelerating, with respect to the reference composition, the catastrophic degradation of the samples during ageing. It follows that the addition of aluminium silicate $(\mathrm{Na})$ does not contribute to materials durability.

Materials containing ultramarine show the highest compressive strength at any time of ageing. Ultramarine and aluminium silicate $(\mathrm{Na})$ have similar composition, their main difference being the presence of $\mathrm{S}_{3}{ }^{-}$ions in ultramarine. Such ions are responsible of instability and reactivity of ultramarine blue which is amplified in the mortars production environment. In fact the environmental conditions caused by the chemical reactions during the hydration process are strongly aggressive. In such environment the $\mathrm{S}_{3}{ }^{-}$radical anion, containing an unpaired electron [25], is greatly reactive and reasonably accelerate some of the hydration processes between the mortars components during production. The mechanical performances of materials containing ultramarine are therefore reasonably due to two synergic phenomena: the first of chemical origin, which depends on the accelerated reactions between some of the mortars components, namely, 
$\mathrm{MgO}$ and $\mathrm{CaO}$ containing compounds [2, 3, 9, 26, 27], during the early stages of hydration when materials are not yet hardened; and the second of physical nature due to the minimized materials open porosity which limits permeability during ageing. However the presence of $\mathrm{Na}$ favours long term ASR which causes a continuous progressive increase of open porosity and reduction of strength. The present results are in agreement with those obtained by other researches which observed a similar behaviour in concrete containing recycled slag [28].

Materials containing chromium oxide display good but not the best properties among all the materials tested in the present research. In fact their absolute performances are inferior to those of the composition containing ultramarine. However, if the ratio between the strength value obtained after $1100 \mathrm{~d}$ of ageing and the maximum strength measured (i.e., after $180 \mathrm{~d}$ ) is evaluated, it can be observed that materials containing chromium oxide reach 0.71 whereas those containing ultramarine show the value of 0.63 . It means that the presence of chromium oxide permits to obtain materials that suffer from a lower decay with respect to the others. This result is in line with the one obtained by other authors who demonstrated that the use of chromium oxide tends to mitigate the ASR [29].

Another detail which emerged from the data reported in present research is that all compositions display an inversion of the trend of compression strength and water absorption after $180 \mathrm{~d}$ of curing. This inversion is reasonably related to the retarded hydration of some compounds and depends on materials permeability which is function of their open porosity. The time required for permeation falls between 180 and $360 \mathrm{~d}$ which therefore depends on the preparation protocol followed and not on materials' composition.

It may be concluded that cement based materials containing coarse steel slag as aggregate can develop good long term compression strength if their permeability is limited. Permeability is promoted by material's residual open porosity which could be limited optimizing preparation. In parallel, the ASR must be limited by reducing the presence of alkalis in the starting components or by the addition of compounds which could limit their negative effects.

\section{Concluding Remarks}

The present research demonstrates that mortars prepared using a commercial CEMIIB-LL cement, coarse $(\varnothing<$ $2.5 \mathrm{~mm}$ ) steel slag as aggregate, Glenium 51 as superplasticizer, and water display good compression strength after ageing for 28,90 , and $180 \mathrm{~d}$ in water at $20^{\circ} \mathrm{C}$ if prepared following a different protocol route with respect to those normally used for the production of mortars or concrete. However, if aged for longer times, several samples spontaneously crumble during ageing due to some localized catastrophic expansion caused by the retarded hydration of some compounds contained in the starting slag.

A limited addition (3 wt $\%$ of the total solid materials content) of further products (i.e., ultramarine blue colour, chromium oxide green colour, and aluminium silicate $(\mathrm{Na})$ ) to the above described blank composition showed that reducing materials residual open porosity and limiting the ASR during ageing lead to optimize long term compressive strength of compositions containing ultramarine and chromium oxide.

\section{Competing Interests}

The authors declare that there is no conflict of interests regarding the publication of this paper.

\section{References}

[1] P. Barnes, C. H. Fentiman, and J. W. Jeffery, "Structurally related dicalcium silicate phases," Acta Crystallographica Section A, vol. 36, no. 3, pp. 353-356, 1980.

[2] M. Chen, M. Zhou, and S. Wu, "Optimization of blended mortars using steel slag sand," Journal Wuhan University of Technology, Materials Science Edition, vol. 22, no. 4, pp. 741-744, 2007.

[3] Y. Lun, M. Zhou, X. Cai, and F. Xu, "Methods for improving volume stability of steel slag as fine aggregate," Journal Wuhan University of Technology, Materials Science Edition, vol. 23, no. 5, pp. 737-742, 2008.

[4] M. Kuhn, P. Drissen, J. Geiseler, and H. J. Schrey, "A new BOF slag treatment technology," in Proceedings of the 2nd European Oxygen Steel Making Congress, pp. 445-453, October 1997.

[5] M. Shigeru, K. Hirohi, and K. Keiichi, "The development of the new ageing process of steel-making slag," SEAISI Quarterly, pp. 37-48, 1997.

[6] A. Fleischanderl, U. Gennari, and A. Ilie, "Revenue from waste: ZEWA-wetallurgical process for treatment of residues from steel industry and other industrial sectors to generate valuable products," Ironmaking and Steelmaking, vol. 31, no. 6, pp. 444449, 2004.

[7] J. Geiseler, "Use of steelworks slag in Europe," Waste Management, vol. 16, no. 1-3, pp. 59-63, 1996.

[8] C. Shi and S. Hu, "Cementitious properties of ladle slag fines under autoclave curing conditions," Cement and Concrete Research, vol. 33, no. 11, pp. 1851-1856, 2003.

[9] I. Akın Altun and I. Yılmaz, "Study on steel furnace slags with high $\mathrm{MgO}$ as additive in Portland cement," Cement and Concrete Research, vol. 32, no. 8, pp. 1247-1249, 2002.

[10] S. Kourounis, S. Tsivilis, P. E. Tsakiridis, G. D. Papadimitriou, and Z. Tsibouki, "Properties and hydration of blended cements with steelmaking slag," Cement and Concrete Research, vol. 37, no. 6, pp. 815-822, 2007.

[11] A. Monshi and M. K. Asgarani, "Producing portland cement from iron and steel slags and limestone," Cement and Concrete Research, vol. 29, no. 9, pp. 1373-1377, 1999.

[12] J. M. Manso, M. Losañez, J. A. Polanco, and J. J. Gonzalez, "Ladle furnace slag in construction," Journal of Materials in Civil Engineering, vol. 17, no. 5, pp. 513-518, 2005.

[13] H. Qasrawi, F. Shalabi, and I. Asi, "Use of low $\mathrm{CaO}$ unprocessed steel slag in concrete as fine aggregate," Construction and Building Materials, vol. 23, no. 2, pp. 1118-1125, 2009.

[14] C. Shi and J. Qian, "High performance cementing materials from industrial slags-a review," Resources, Conservation and Recycling, vol. 29, no. 3, pp. 195-207, 2000.

[15] M. M. Shoaib, M. M. Balaha, and S. A. Ahmed, "Influence of aggregate type on mortar thermal stability," Indian Journal of Engineering and Materials Sciences, vol. 7, no. 4, pp. 217-224, 2000 . 
[16] N. Faraone, G. Tonello, E. Furlani, and S. Maschio, "Steelmaking slag as aggregate for mortars: effects of particle dimension on compression strength," Chemosphere, vol. 77, no. 8, pp. 11521156, 2009.

[17] J. Péra, S. Husson, and B. Guilhot, "Influence of finely ground limestone on cement hydration," Cement and Concrete Composites, vol. 21, no. 2, pp. 99-105, 1999.

[18] P. Wainwright and H. Ait-Aider, "The influence of cement source and slag additions on the bleeding of concrete," Cement and Concrete Research, vol. 25, no. 7, pp. 1445-1456, 1995.

[19] E. Furlani and S. Maschio, "Steel scale waste as component in mortars production: An Experimental Study," Case Studies in Construction Materials, vol. 4, pp. 93-101, 2016.

[20] C. L. Hwang and C. Y. Lin, "Strength development of blended blast furnace slag cement mortars, SP 91-65," in Proceedings of the 2nd International Conference on Fly Ash, Silica Fume, Slag and Natural Pozzolans in Concrete, V. M. Malhotra, Ed., vol. 2, pp. 1323-1340, American Concrete Institute, Madrid, Spain, 1986.

[21] D. G. Mantel, "Investigation into the hydraulic activity of five granulated blast furnace slags with eight different portland cements," ACI Materials Journal, vol. 91, no. 5, pp. 471-477, 1994.

[22] S. C. Pal, A. Mukherjee, and S. R. Pathak, "Investigation of hydraulic activity of ground granulated blast furnace slag in concrete," Cement and Concrete Research, vol. 33, no. 9, pp. 14811486, 2003.

[23] H. G. Smolczyk, "The effect of chemistry of slag on the strength of blast furnace cements," Zem.-Kalk-Gips, vol. 31, no. 6, pp. 294-296, 1978

[24] M. Maslehuddin, A. M. Sharif, M. Shameem, M. Ibrahim, and M. S. Barry, "Comparison of properties of steel slag and crushed limestone aggregate concretes," Construction and Building Materials, vol. 17, no. 2, pp. 105-112, 2003.

[25] G. Buxbaum, H. Printzen, M. Mansmann et al., "Pigments, inorganic, 3. Colored pigments," in Ullmann's Encclopedia of Industrial, John Wiley \& Sons, New York, NY, USA, 2009.

[26] M. B. Haha, B. Lothenbach, G. Le Saout, and F. Winnefeld, "Influence of slag chemistry on the hydration of alkali-activated blast-furnace slag - part I: effect of MgO," Cement and Concrete Research, vol. 41, no. 9, pp. 955-963, 2011.

[27] V. S. S. Birchal, S. D. F. Rocha, and V. S. T. Ciminelli, "Effect of magnesite calcination conditions on magnesia hydration," Minerals Engineering, vol. 13, no. 14-15, pp. 1629-1633, 2000.

[28] M. Al-Mehthel, M. Maslehuddin, S. Al-Idi, M. A. Rizwan, and M. B. Salihu, Sulfur steel slag aggregate concrete, U.S. Patent 8652251B2, 2014.

[29] G. Blumenstyk, "A concrete use for discarded beer bottles (and Other Recycled Glass)," Chronicle of Higher Education, vol. 50, no. 4, article A28, 2003. 


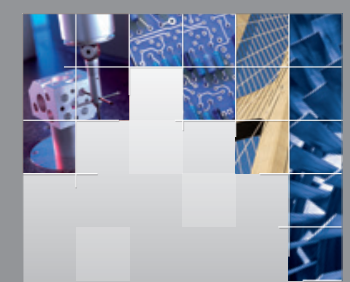

\section{Enfincering}
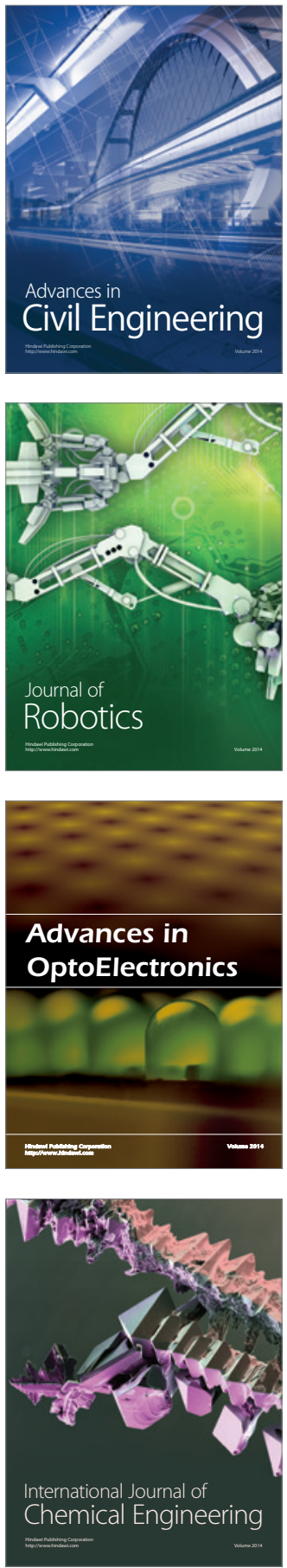

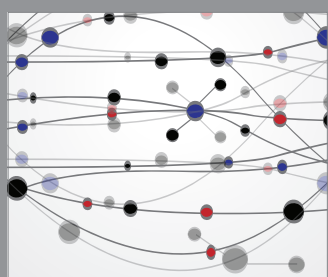

The Scientific World Journal

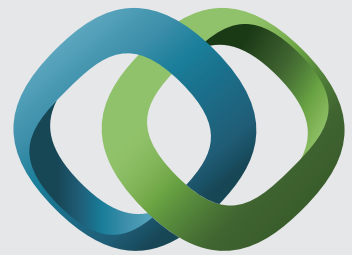

\section{Hindawi}

Submit your manuscripts at

http://www.hindawi.com
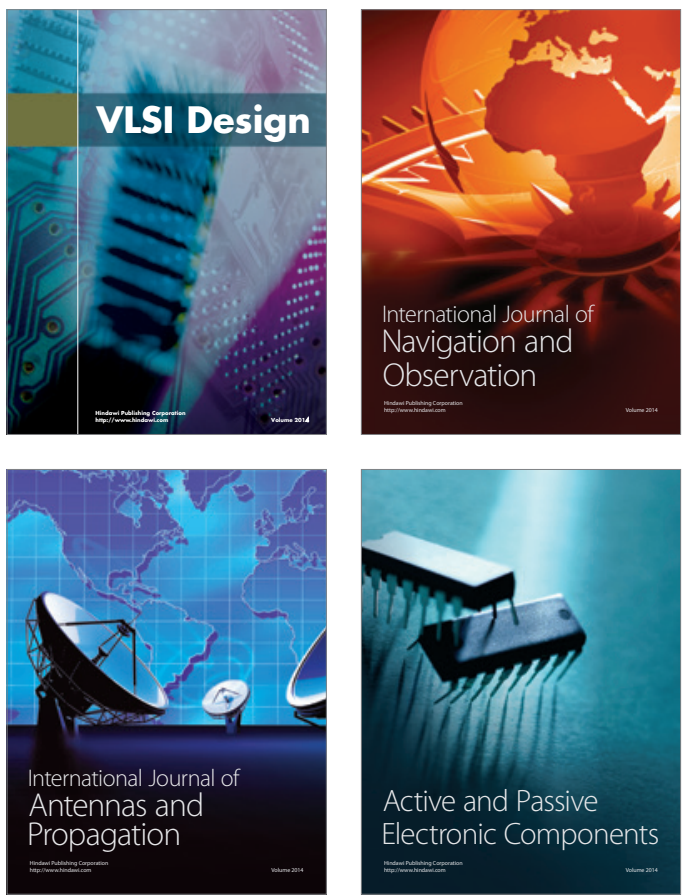
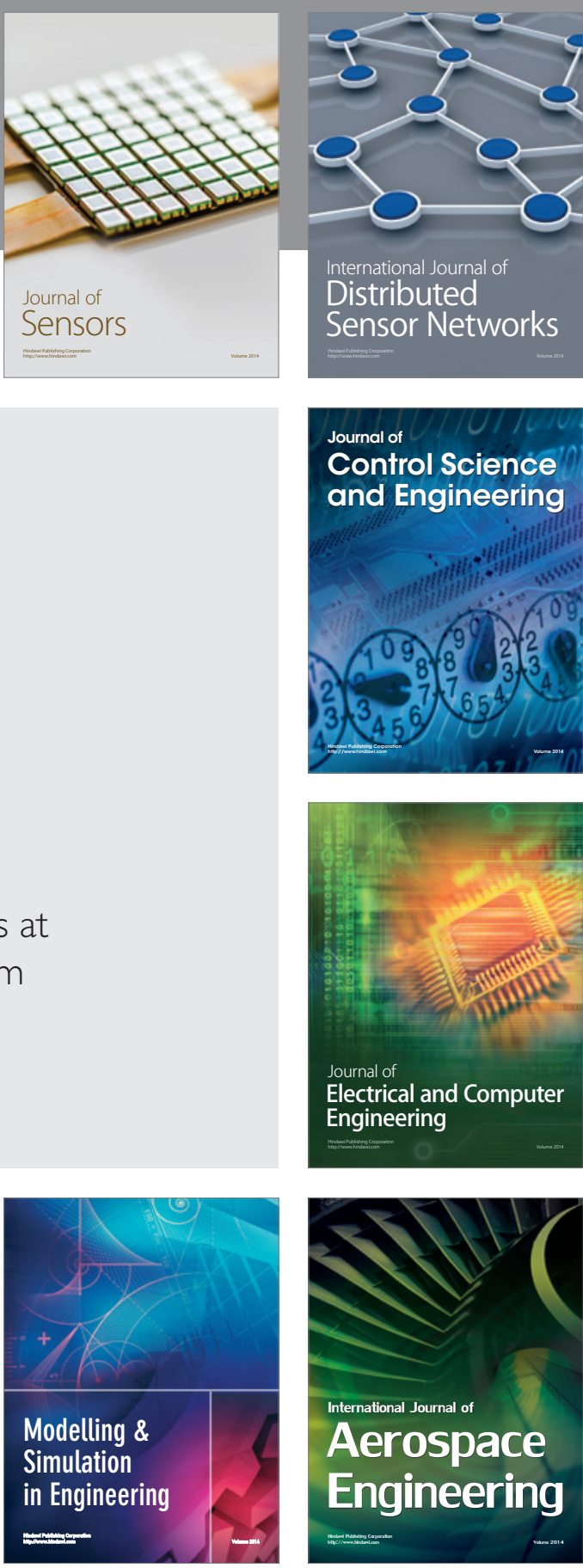

International Journal of

Distributed

Sensor Networks

Journal of

Control Science

and Engineering
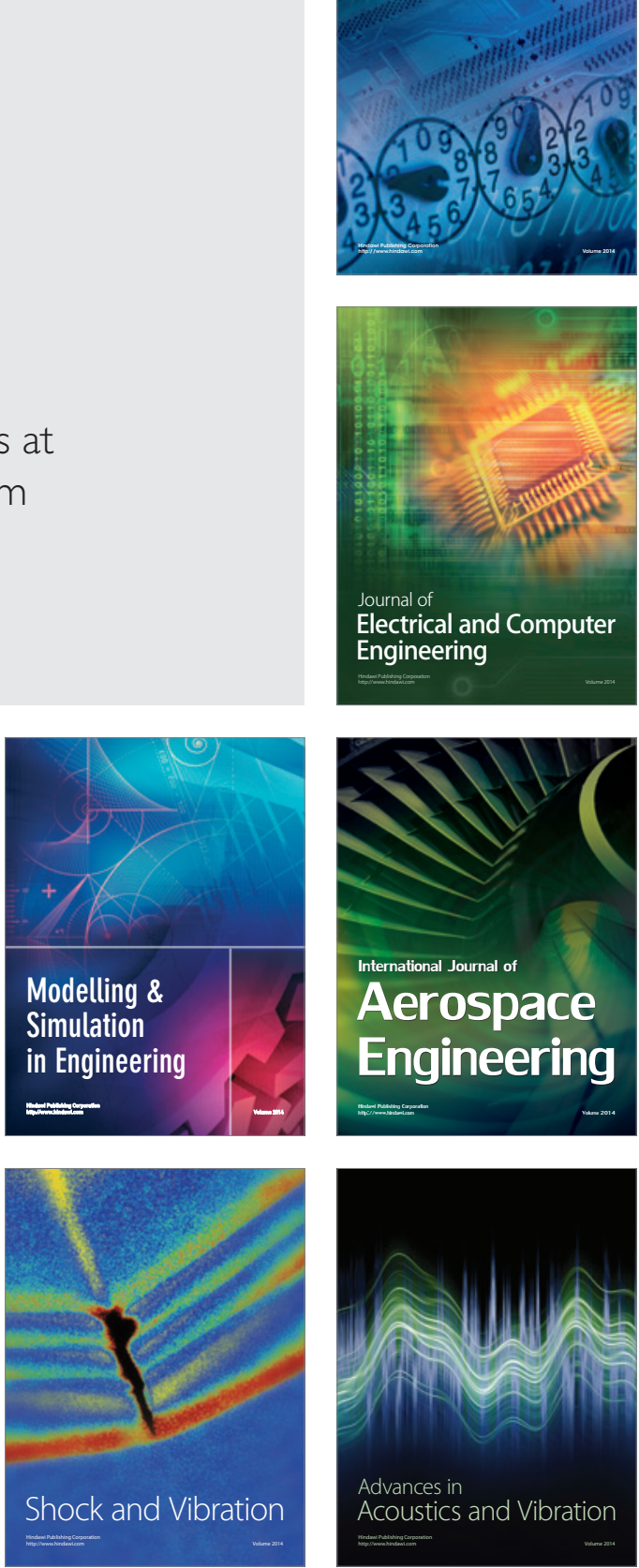